\title{
К вопросу разработки устройства для сортировки картофеля
}

\author{
Н.Н. Романюк ${ }^{1}$, В.Н. Еднач, В.А. Агейчик, С.М. Лакутя \\ Учреждение образования «Белорусский государственный аграрный \\ технический университет», (е. Минск, Республика Беларусь) \\ e-mail: ${ }^{1}$ romanyuk-nik@tut.by
}

\begin{abstract}
Картофель является одной из немногих сельскохозяйственных культур, обеспечивающих питание населения и продовольственную безопасность страны. Высокая значимость этого продукта подтверждается постоянным ростом его производства в мире и стабильным спросом. В статье рассматриваются вопросы, связанные с разработкой конструкции технического средства для сортировки картофеля. Предложена оригинальная конструкция устройства для сортировки клубнеплодов, использование которого позволит повысить производительность и качество разделения клубнеплодов картофеля по фракциям.
\end{abstract}

Ключевые слова: клубнеплоды, картофель, сортировка, оригинальное устройство, патентный поиск, производительность, качество разделения, фракции.

Введение. Картофель - одна из важнейших и распространенных культур в сельскохозяйственном производстве. Роль картофеля в решении мировой продовольственной проблемы очень велика, поскольку он - продовольственная культура с высокой питательной ценностью и продуктивностью.

Республика Беларусь является одним из ведущих производителей и поставщиков картофеля, и на ее долю приходится 4-6\% ежегодного мирового объема производства клубней, а среди стран СНГ - 13-15\%. В прошлые годы за пределы республики вывозилось более 450 тыс. т продовольственных и 200-250 тыс. т семенных клубней. В настоящее время отрасль выполняет социальную функцию, при низкой ее товарности население занято самообеспечением картофелем [1].

Валовые сборы картофреля в Республике Беларусь стабильно составляют 9 млн т. На душу населения его производится около $1 \mathrm{~T}$, что является одним из самых высоких показателей в мире. Вместе с тем, при относительной стабильности и высоком уровне производства, формирование рынка картофеля по ряду причин остается проблематичным [1].

Площадь возделывания картофеля по интенсивной технологии должна быть не менее 200 тыс. га (примерно 30 \% всех посевов культуры), в т. ч. семеноводческие посевы для плановой сортосмены и сортообновления - 7075 тыс. га, товарный продовольственный - 5560 и на технические цели - 65-70 тыс. га [1].

В соответствии с Государственной программой развития аграрного бизнеса в Республике Беларусь на 2016-2020 годы задачей подкомплекса картофелеводства является наращива- ние объемов производства картофреля к концу 2020 года за счет внедрения интенсивных технологий возделывания, сокращения потерь при уборке и послеуборочной доработке и хранении.

Одной из актуальных проблем при производстве картофеля является его качественная послеуборочная доработка. Многочисленными исследованиями установлено, что повреждения клубней картофеля только в результате одной операции сортировки могут достигать $20 \%$ [3]. Нарушение технологии послеуборочной доработки, особенно сортировки, приводит к существенным потерям товарных и семенных качеств картофеля за счет пересортицы. Поэтому важной задачей повышения эффрективности доработки картофеля является как улучшение точности калибрования, так и предотвращение повреждений клубней рабочими органами [2].

Актуальность исследования обусловлена необходимостью изменения техники для сортирования и калибрования картофеля.

Новизной исследований является постановка нового подхода к данной проблеме. В связи со сказанным целью исследований является разработка устройства для сортировки клубнеплодов, способного повысить производительность и качество разделения клубнеплодов картофеля по фракциям.

Для решения поставленной цели нами поставлены следующие задачи исследований:

1 Провести патентные исследования и проанализировать технические средства для сортировки клубнеплодов.

2. Разработать конструкцию устройства для сортировки клубнеплодов, использование кото- 
рого позволит повысить производительность и качество разделения клубнеплодов картофеля по фракциям.

\section{Основная часть}

Реализация поставленных задач исследований осуществлена следующим образом.

Показателями качества работы машин для сортировки картофеля являются точность разделения на фракции и количество повреждений, наносимых клубням рабочими органами. Основной причиной повреждений клубней картофеля на калибрующих поверхностях сортировальных машин является защемления и последующая деформация клубней роликами при проходе сквозь калибрующее отверстие. При этом наибольшие повреждения получают клубни овальной и плоской формы. Рассмотрев взаимодействие клубня с роликами (рисунок 1) установлено, что при повороте клубня на угол $\theta_{1}=\theta_{2}$ относительно каждого из роликов расстояние, на которое произошло смещение точек первоначального контакта клубня с роликами, различно: $\Delta / 1 \neq \Delta / 2$.

Из схемы взаимодействия клубня овальной формы с роликами (см. рисунок 1) следует, что с увеличением эллиптичности формы клубня неравномерность его перемещения относительно роликов увеличивается, приводя к проскальзыванию, а если сила трения $F_{1}>F_{2}$, то происходит защемление клубня. Для предотвращения защемления необходимо увеличение скорости ролика с центром $0_{2}$, которое компенсирует эллиптичность формы клубня. При этом он будет выкатываться из впадины по ролику с центром $0_{1}$, имеющему меньшую окружную скорость.

Следовательно, при определении скоростных режимов роликов необходимо учитывать форму клубня посредством коэфффициента, отражающего степень отношения его ширины к толщине. Коэффициент формы определяется по выражению

$$
\mathrm{K}_{\mathrm{p}}=\frac{\mathrm{c}_{\mathrm{K}}}{b_{\mathrm{K}}}
$$

где $c_{\kappa}$ - толщина клубня, м; $b_{\text {к }}$ ширина клубня, м.

Исследование движения клубня эллиптической формы на роликовой поверхности позволило определить приращение скорости каждого последующего ролика $V_{\text {вых }}$ позволяющее предотвратить защемление клубней:

$$
V_{\text {вых }}=2 \cdot \pi \cdot n_{N-1} \cdot R_{N-1} \frac{\left(r_{b}-r_{C}\right)}{r_{\mathrm{C}}},
$$

где $n_{N-1}$ - частота вращения предыдущего ролика, $\mathrm{c}^{-1} ; R_{N-1}-$ радиус предыдущего ролика, м; $r_{b}$ - радиус клубня по ширине, м; $r_{c}$-радиус клубня по толщине, м.

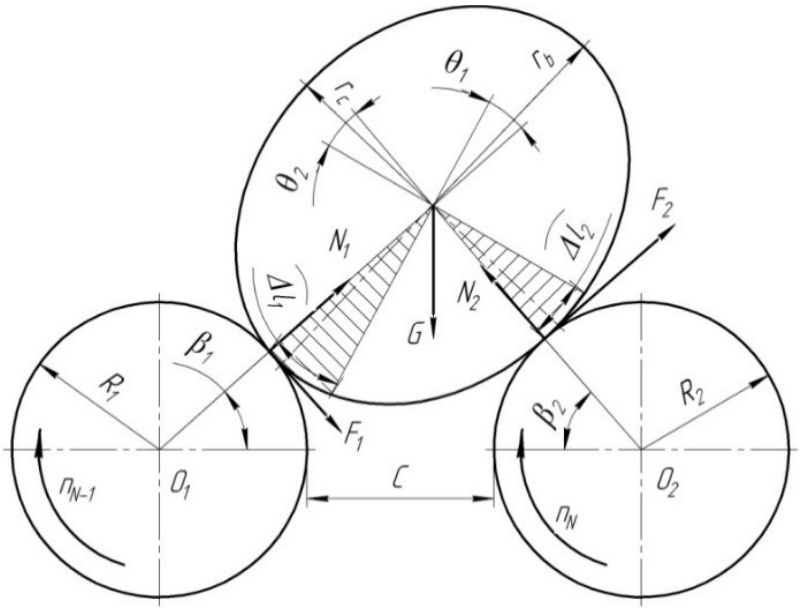

Рис. 1. Схема взаимодействия клубня овальной формы с роликами

В паре роликов, образующих ручей, скорость последующего ролика $V_{N}$ выше скорости предыдущего $V_{N-1}$ на приращение $V_{\text {вых}}$, учитывающее коэффициент фоормы клубня $K_{p}$ посредством передаточного отношения $i$ между роликами, которое определяется по выражению

$$
i=\frac{n_{N-1}}{n_{N}}=\frac{V_{N-1}}{V_{N}}=\frac{r_{\mathrm{c}}}{r_{b}}=\frac{\mathrm{c}_{\mathrm{\kappa}}}{b_{\mathrm{K}}}=\mathrm{K}_{\mathrm{p}},
$$

где $n_{N}$ - частота вращения последующего ролика, $\mathrm{c}^{-1}$.

Исследование движения клубня по калибрующей поверхности с продольным положением роликов позволило установить, что закономерность движения клубня отражает след точек контакта его с роликами, представляющий собой спираль. Развертка витка спирали характеризуется углом подъема винтовой линии следа контакта $\Psi$ и шагом $H$, которые определяются из соотношения продольной и поперечной скоростей клубня. Поскольку существенное влияние на характер движения клубней оказывает их форма, то в исследованиях рассматривались клубни округлой и овальной фрормы.

Анализ движения клубней округлой формы (рисунок 2), с учетом угловых скоростей клубня вдоль $\left(\omega_{\kappa}\right)$ и поперек $(\omega)$ роликов, момента инерции I, веса $G$, нормальных реакций $N_{1}, N_{2}, N_{\text {в }}$ с сил трения скольжения поперек $\left(F_{1}, F_{2}\right)$ и вдоль $\left(F_{1}^{\prime}\right.$,

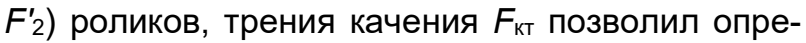
делить скорость движения клубня

$$
V_{\text {кл }}=\sqrt{+\frac{g \cdot L(\sin \alpha-f \cdot \cos \alpha) 10 \cdot r^{2}{ }_{\text {кач }}}{5 \cdot r^{2}{ }_{\text {кач }}+2 \cdot R_{\mathrm{K}}{ }^{2}}},
$$

где $V_{\text {кл }}$ - скорость клубня, м/c; $n$ - частота вращения ролика, $\mathrm{c}^{-1} ; R$ - радиус ролика, м; $g$ - ускоре- 


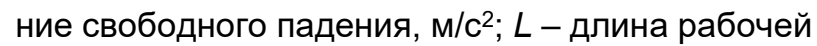
поверхности, м; $\alpha$ - угол установки поверхности к горизонту, градусы; $f$ - коэфффициент трения; $r_{\text {кач }}$ - радиус качения клубня, м; $R_{\kappa}$ - радиус клубня, м.

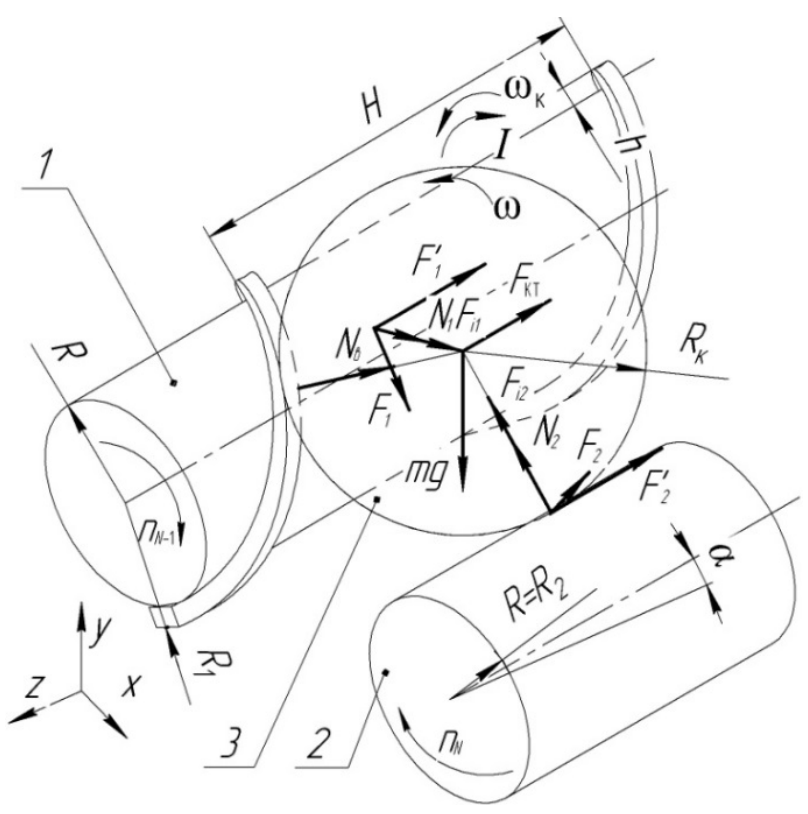

Рис. 2. Схема положения клубня округлой формы на роликах

После преобразования выражения (4) шаг спирали следа клубня округлой фрормы можно определить по выражению

$$
H=n^{-1} \sqrt{\frac{g \cdot L(\sin \alpha-f \cdot \cos \alpha) 10 \cdot r_{\text {кач }}^{2}}{5 \cdot r^{2}{ }_{\text {кач }}+2 \cdot R_{K}{ }^{2}}} .
$$

Закономерность движения клубней плоской и овальной формы представляет собой цикличность подъема по образующей ролика на угол $\beta_{2}$ (см. рисунок 1) и соскальзывания в зазор между роликами. Их скорость значительно ниже скоростей клубней округлой фрормы. Скорость $V_{\text {т. кл } и}$ шаг спирали $H_{\text {T }}$ для клубней плоской формы определены из условия скольжения по ролику:

$$
\begin{gathered}
V_{\text {т.кл }}=\frac{2 \cdot \pi \cdot n \cdot R \cdot \operatorname{tg} \alpha}{\cos \beta_{2}}, \\
H_{m}=\frac{2 \cdot \pi \cdot R \cdot \operatorname{tg} \alpha}{\cos \beta_{2}} .
\end{gathered}
$$

Поскольку клубни округлой формы движутся гораздо быстрее, чем плоской, то для стабилизации производительности поверхности необходимо использовать спиральную навивку. Шаг спиральной навивки лежит в интервале от $H$ до

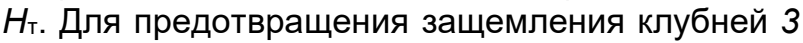

(рис. 2) навивками соседних роликов необходимо применение чередования роликов с навивкой 1 и гладких 2.

Проведенный патентный поиск показывает, что известна роликовая сортирующая поверхность, включающая раму, установленные на ней с возможностью принудительного вращения в одном направлении параллельные ролики, причем со стороны подачи клубнеплодов перпендикулярно его направлению расположены гладкие ролики, а далее, последовательно, - фигурные ролики для отделения мелкой и средней фракций [3, с. 46].

Такая роликовая сортирующая поверхность не обеспечивает требуемую производительность технологического процесса, так как, несмотря на то, что гладкие ролики при поступлении клубнеплодов способствуют более равномерному распределению картофеля вдоль них, сам процесс преодоления клубнями роликов в направлении, перпендикулярном их осям, носит случайный характер и обусловлен как воздействием вышерасположенных клубнеплодов, так и размерами роликов и клубнеплодов, а также постоянно меняющейся формой поверхностей клубнеплодов и коэффициентом трения их о поверхности роликов [3, с. 30-37].

Известна роликовая сортирующая поверхность [1, с. 29], включающая раму; установленные на ней с возможностью вращения, выполненные в виде усеченных конусов и установленные большими основаниями со стороны подачи клубнеплодов с параллельными ему и друг другу осями ролики; привод, позволяющий осуществлять попарное вращение верхних поверхностей роликов в противоположные от центральной оси симметрии пары стороны, что исключает защемление между роликами клубнеплодов с последующим их повреждением.

Такая роликовая сортирующая поверхность обеспечивает требуемую производительность технологического процесса одной пары конических роликов, так как существенных препятствий, при наличии достаточного наклона сортирующих поверхностей, продвижению клубнеплодов не существует. Однако при одновременном использовании на роликовой сортирующей поверхности расположенных вплотную и параллельно друг другу нескольких пар роликов значительная часть сортирующей поверхности не может быть задействована, так как в зоне стыка различных пар вращение верхних частей соседних роликов будет направлено навстречу друг другу, и, для исключения случаев защемления клубнеплодов, 
эти зоны должны быть закрыты оградительными щитами, исключающими попадание в них клубнеплодов. Выполнение поверхности ската клубнеплодов в виде соседствующих конических поверхностей затрудняет точное разделение картофеля по фракциям, так как в силу сложной формы клубнеплодов и непостоянства коэффициентов трения между клубнеплодами и роликами при малых углах наклона будет наблюдаться резко снижающая производительность скученность клубнеплодов, а при незначительном увеличении этих углов возможно лавинообразное скатывание клубней картофеля, при котором они, даже при наличии соответствующего размера, не будут успевать проходить между роликами.

В Белорусском государственном аграрном техническом университете разработана оригинальная конструкция устройства для сортировки клубнеплодов [4] (рисунок 3).

Устройство для сортировки клубнеплодов содержит раму 1, на которой установлены с возможностью вращения параллельные своими осями друг другу и направлению подачи клубнеплодов, например, картофеля с транспортера 2 ролики 3, наклоненные вниз по направлению подачи на угол а, меньший угла трения клубнеплодов о ролики 3, которые выполнены с уменьшающимися по направлению подачи клубнеплодов диаметрами секций в соответствии с количеством разделяемых фракций.

Ролики 3 приводятся во вращение с помощью привода в составе закрепленных на раме 1 электромотора 4 с установленной на его валу ведущей звездочкой 5, закрепленных на валах роликов 3 со стороны их больших диаметров ведомых звездочек 6 одинакового размера, направляющих 7 и натяжной 8 звездочек, а также охватывающей их втулочнороликовой цепи 9, которая относительно этих звездочек установлена таким образом, что относительно центральной продольной оси симметрии, образованной роликами сортировальной поверхности, верхние части роликов имеют одностороннее и противоположное относительно этой оси вращение. Диаметры роликов 3 , по мере увеличения их расстояния от центральной продольной оси симметрии сортировальной поверхности, увеличиваются, верхние образующие роликов 3 в каждой секции находятся в одной плоскости, а ролики 3 через один в каждой секции имеют противоположные направлению их вращения навивки 10 и 11 в виде эластичных выступов скругленной формы, исключающих защемление и повреждение клубнеплодов, с шагом не менее зазора между поверхностями роликов 3 соответствующей секции. Над крайними роликами в их центральной части по всей длине установлены параллельные осям роликов 3 упругие ограждающие борта 12 . Под секциями сортировальной поверхности установлены по направлению подачи клубнеплодов емкости (транспортеры) для сбора (отвода), соответственно, примесей (I), мелкой фрракции (II), средней фрракции (III) и, за пределами сортировальной поверхности, крупной фракции (IV) картофеля.

Устройство работает следующим образом.

Клубнеплоды транспортером 2 подаются на сортировальную поверхность, образованную роликами 3, в секцию их наибольших диаметров и наименьших зазоров между ними. Поскольку клубнеплоды на транспортере 2 в сечении, перпендикулярном направлению движения, расположены в соответствии с законами статики и динамики сыпучей среды по форме, близкой к треугольной, то наибольшее их количество поступит на центральные, вращающиеся в разные стороны ролики 3. Здесь клубнеплоды захватываются навивками 9 и 10 в виде эластичных выступов с шагом не менее зазора между поверхностями вальцов секции и продвигаются ими вдоль роликов 3. Этому также способствует наклон роликов 3 вниз по направлению подачи, и так как угол их наклона а меньше угла трения клубнеплодов о ролики 3, то при этом не происходит лавинообразного скатывания клубнеплодов вниз, чему, в свою очередь, также препятствуют навивки 9 и 10.

Одновременно клубнеплоды распределяются по сортировальной поверхности в поперечном направлении согласно направлению вращения роликов 3, при этом наличие более одного слоя клубнеплодов вблизи центральной продольной оси симметрии сортировальной поверхности не препятствует этому движению [3, c. 32-34], а при определенных условиях даже способствует ему. По мере удаления от центральной продольной оси в поперечном направлении клубнеплоды во все возрастающей степени располагаются на сортировальной поверхности в один слой. Так как диаметры роликов 3 в этом направлении возрастают, при постоянной скорости цепи 9 и одинаковых размерах ведущих звездочек окружная скорость контактируемых с клубнеплодами поверхностей роликов 3 также возрастает.

При этом скорость прохождения клубнеплодами роликов 3 в поперечном направлении, в силу уменьшения угла наклона плоскости, 
касательной к ролику в точке контакта его с клубнеплодом, по которой клубнеплод перемещается в момент преодоления им ролика [3, с. 30-31], также увеличивается.

Таким образом, по мере удаления от центральной продольной оси сортировальной поверхности в поперечном направлении клубнеплоды эффективно преодолевают роликовые поверхности в этом направлении и затем ударяются об упругие ограждающие борта 12. Так как поверхность клубнеплодов имеет сложную форму, и в силу других случайных фракторов, отскакивающие от упругих ограждающих бортов 12 клубнеплоды распределяются по сортировальной поверхности с высокой степенью равномерности.

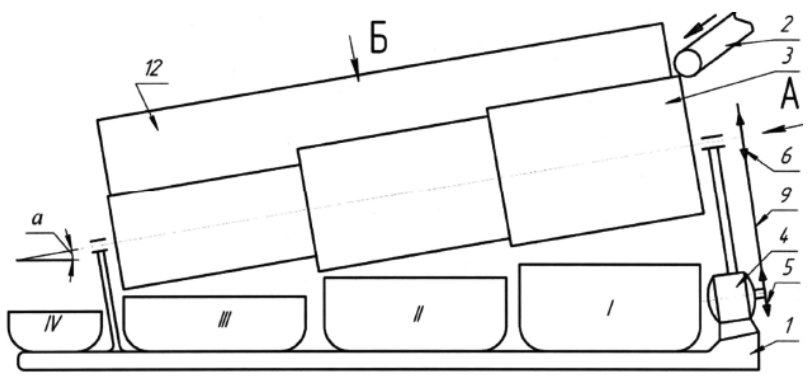

a)

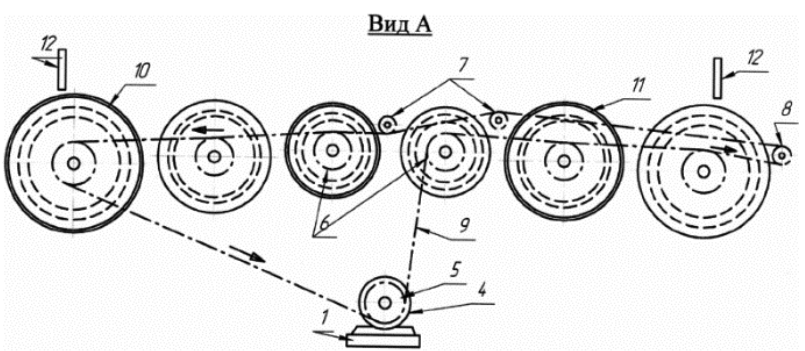

б)
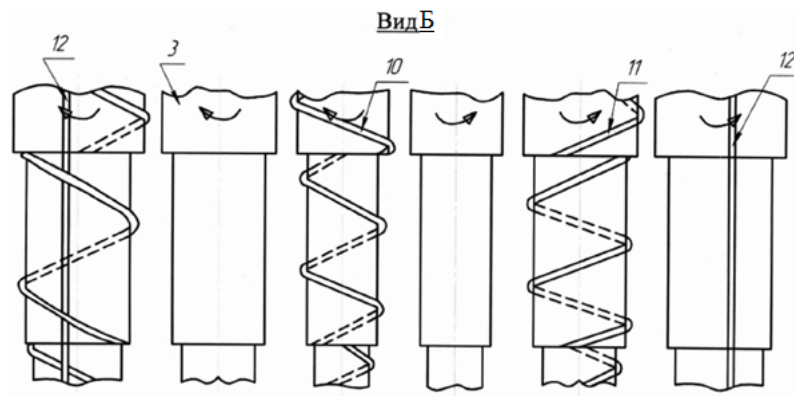

B)

Рис. 3. Устройство для сортировки клубнеплодов а) - общий вид устройства;

$$
\text { б) - вид А; в) - вид } Б
$$

Это способствует эффрективной загрузке, высокой производительности устройства и высокой степени качества сортировки клубнеплодов, так как вышеописанная картина характерна для всех секций сортировки, отделяющих различные по размеру фракции клубнеплодов картофреля.

\section{Выводы}

1. Проанализированы технические средства для сортировки клубнеплодов.

2. Предложена оригинальная конструкция устройства для сортировки клубнеплодов, использование которого позволит повысить производительность и качество разделения клубнеплодов картофеля по фракциям.

\section{Литература}

1. Особенности рынка картофеля в Республике Беларусь [Электронный ресурс]. - URL: https://studbooks.net/1064911/agropromyshlennost losobennosti_rynka_kartofelya_respublike_belarus. - Дата обращения: 22.10.2018.

2. Еднач, В.Н. Повышение качества калибрования картофеля поверхностью с изменяющейся скоростью вращения роликов: автореф. дис. ... канд. техн. наук: 05.20.01 / В.Н. Еднач; Белорус. гос. аграр. техн. ун-т. - Минск, 2018. - 24 с.

3. Колчин, Н.Н. Машины для сортирования и послеуборочной обработки картофеля / Н.Н. Колчин, В.П. Трусов. - М. : Машиностроение, 1966. - 256с.

4. Устройство для сортировки плодов: пат. 14557 Респ. Беларусь, МПК А 01D 33/00 / А.Л. Рапинчук, В.Н. Еднач, А.А. Шупилов, В.А. Агейчик; заявитель РУП «НПЦ НАН Беларуси по механизации сельского хоз-ва». - № а 20080533; заявл. 30.12.2009; опубл. 30.06.2011 // Афріцыйны бюл. / Нац. цэнтр інтэлектуал. уласнасці. - 2011. - № 3. - C. 45-46.

\section{References}

1 Studbooks.net. (2018). Osobennosti rynka kartofelia v Respublike Belarus. [online] Available at: https://studbooks.net/1064911/agropromyshlennost/osobennosti_rynka_kartofelya_respublike_belarus [Accessed $2 \overline{2}$ Oct. 2018$]$

2. Ednach, V. (2018). Povyshenie kachestva kalib-rovaniia kartofelia poverkhnostiu s izmeniaiushcheisia skorostiu vrashcheniia rolikov. Minsk: Belarusian State Agrarian Technical University, p.24

3. Kolchin, N. and Trusov, V. (1966). Mashiny dlia sortirovaniia $i$ posleuborochnoi obrabotki kartofelia. Moscow: Mashinostroenie, p.256. 3

4 Rapinchuk, A., Ednach, V., SHupilov, A. and Ageichik, V. (2011). Ustroistvo dlia sortirovki plodov A 01D 3300. Patent \#14557 National Center of Intellectual PropertyRepublic of Belarus. 
Анотація

\title{
До питання розробки пристрою для сортування картоплі
}

\author{
М.М. Романюк, В.М. Еднач, В.А. Агейчик, С.М. Лакутя
}

Картопля є однією з небагатьох сільськогосподарських культур, що забезпечують харчування населення і продовольчу безпеку країни. Висока значимість цього продукту підтверджується постійним зростанням його виробництва в світі і стабільним попитом. У статті розглядаються питання, пов'язані 3 розробкою конструкції технічного засобу для сортування картоплі. Запропоновано оригінальну конструкцію пристрою для сортування клубнеплодов, використання якого дозволить підвищити продуктивність і якість поділу клубнеплодов картоплі по фракціям.

Ключові слова: бульбоплоди, картопля, сортування, оригінальний пристрій, патентний пошук, продуктивність, якість поділу, фракції.

\section{Abstract}

\section{Regarding the question of the devices' development for sorting potatoes}

\author{
N.N. Romaniuk, V.N. Ednach, V.A. Ageichik, S.M. Lakutia
}

Potato is one of the few agricultural crops that provides nutrition for population and food security of the country. The high importance of this product is confirmed by the constant growth of its production in the world and stable demand. The article deals with the issues related to the development of the design of technical equipment for sorting potato. The original design of the device to sort tubers, the use of which will improve performance and quality of the separation of potato tubers into fractions.

Keywords: tuber crops, potatoes, sorting, original device, patent search, performance, quality of separation, fractions.

\section{Бібліографічне посилання/ Bibliography citation: Harvard}

Romaniuk, N., Ednach, V., Ageichik, V. and Lakutia, S. (2019). Regarding the question of the devices' development for sorting potatoes. Engineering of nature management, (3(13), pp. 67-72.

Подано до редакції / Received: 27.05.2019 